\title{
Magnesium in Women's Health and Gynecology
}

\author{
Shawna Tonick1 ${ }^{1}$, Ozgul Muneyyirci-Delale ${ }^{2,3}$ \\ ${ }^{1}$ Department of Obstetrics and Gynecology, Hofstra Northwell School of Medicine, New Hyde Park, USA \\ ${ }^{2}$ Department of Obstetrics and Gynecology, SUNY Downstate Medical Center, Brooklyn, USA \\ ${ }^{3}$ Department of Obstetrics and Gynecology, Kings County Hospital Center, Brooklyn, USA \\ Email: stonick@nshs.edu, Ozgul.Muneyyirci-Delale@downstate.edu
}

Received 26 February 2016; accepted 25 April 2016; published 28 April 2016

Copyright (C) 2016 by authors and Scientific Research Publishing Inc.

This work is licensed under the Creative Commons Attribution International License (CC BY).

http://creativecommons.org/licenses/by/4.0/

(c) (i) Open Access

\begin{abstract}
Magnesium is well known in the world of obstetrics for many important uses. It has been utilized in treating pre-eclampsia, eclampsia, and preventing preterm labor, though it has been found recently that prolonged magnesium administration in pregnant women may result in adverse outcomes to fetal bone metabolism, resulting in a new FDA warning [1]. Outside of obstetrics, magnesium is recommended for treating the arrhythmias torsades de pointes and rapid atrial fibrillation, treating severe acute asthma, improving migraine symptoms, and for treating dyspepsia and constipation [2]. Many women in our modern society are magnesium deficient due to low dietary intake, and low dietary magnesium intake resulting in hypomagnesaemia has recently been shown to have many deleterious effects. Magnesium's uses are wide-reaching, touching many areas of women's health and gynecology from pre-menstrual syndrome to menopause, PCOS to endometriosis, and beyond.
\end{abstract}

\section{Keywords}

Magnesium, Calcium, Hypomagnesemia, Women's Health

\section{Introduction}

Magnesium is the fourth most abundant essential mineral and the second most abundant intracellular divalent cation. It is involved as a cofactor for over 300 metabolic reactions in the body. Approximately $99 \%$ of total body magnesium is intracellular, with $85 \%$ stored in bone; only $1 \%$ is found within the extracellular space. Of magnesium present in serum, approximately $70 \%$ exists in the ionized (free) form, which is crucial to multiple physiologic processes [3]. Of these physiological processes, magnesium is involved in crucial processes such as 
protein synthesis, adenylate cyclate synthesis, oxidative phosphorylation, cellular energy production and storage, preservation of cellular electrolyte composition, cell growth and reproduction, DNA and RNA synthesis, and stabilization of mitochondrial membranes [4]. In addition to its important role in cell biology and genetics, magnesium is also involved in bone metabolism, regulation of parathyroid hormone (PTH) secretion, nerve transmission, cardiac excitability, neuromuscular transduction, muscular contraction, vasomotor tone, and blood pressure regulation. Therefore, magnesium has demonstrated a wide range of possible effects on the human body that can thus affect women's health [5]-[7].

While magnesium is a crucial part of human biology, magnesium deficiency is widespread across different populations, as dietary magnesium intake has decreased dramatically, especially in the western world [2]. Some foods that are rich in magnesium are dark leafy green vegetables, beans, nuts, seeds, fish, whole grains, and dairy; these foods are often not heavily present in many western diets. A study of dietary intake of magnesium in US adults showed that women have a lower dietary intake of magnesium than men. Many women are deficient in magnesium due to both the highly processed magnesium-poor western diet and water softeners and purifiers that strip magnesium out of the drinking water supply. Furthermore, magnesium intake decreases with age. Of note, Caucasians have a significantly higher mean dietary intake of magnesium compared to African Americans [8]. In addition to dietary factors, many commonly prescribed medications can also lead to hypomagnesemia, such as diuretics (both loop and thiazide) and antimicrobials such as aminoglycosides, in addition to proton pump inhibitors that may decrease nutrient absorption; all of these medications are frequently in use among patients. Additionally, many chronic and acute illnesses can trigger magnesium wasting.

Magnesium deficiency may exacerbate chronic inflammatory stress and contribute to conditions such as atherosclerosis, diabetes, and osteoporosis [9]. In rats, inflammation has been found to occur during experimental magnesium deficiency; this low magnesium state also induces hypertriglyceridemia, atherogenesis, platelet aggregability, increased thrombotic events, and increased oxidative stress. It is hypothesized that magnesium deficiency may affect intracellular calcium homeostasis, linking inflammation and metabolic syndrome [10]. There is an inverse relationship between serum magnesium level and high-sensitivity C-reactive protein, an inflammatory marker. Decreased magnesium levels are associated with increased metabolic syndrome risk, as obesity itself is a low-grade inflammation process [11]. Regarding the role of hypomagnesemia in inflammation, adults with hypomagnesemia are found to have elevated CRP levels, while individuals with both hypomagnesemia and metabolic syndrome are also found to have elevated CRP levels [12]. The effects of magnesium on obesity are crucial to women's health, since women are more likely to be obese than men. Higher intake of magnesium is associated with lower BMI in middle aged US men and women, further supporting the link between low magnesium and obesity [13].

Magnesium's role in metabolic syndrome extends to diabetes mellitus. Higher magnesium intake may reduce the risk of developing type 2 diabetes mellitus [14]. Patients with non-insulin dependent diabetes and hypertension have been found to have poor intracellular magnesium concentrations. Magnesium can affect the role of insulin in a few ways. Insulin may modulate the shift of magnesium from extracellular to intracellular spaces; additionally, intracellular magnesium modulates insulin action by offsetting calcium-related excitation contraction coupling and decreasing smooth cell responsiveness to depolarizing stimuli [15]. Obese individuals with metabolic syndrome also commonly have low magnesium in serum and mononuclear cells, especially in nonwhite patients with insulin resistance. It is hypothesized that this hypomagnesemia may contribute to post-receptor insulin resistance on cells [16]. Magnesium may have a therapeutic role for diabetics in the future; experimental trials of $2.5 \mathrm{~g}$ magnesium chloride daily has also been found to improve the ability of beta cells to compensate for variations in insulin sensitivity in non-diabetic women with significant hypomagnesemia [17].

In addition to its role in obesity and diabetes, magnesium intake is associated with reduced mortality from cardiovascular disease in Japanese populations, especially women [18]. The biochemical basis behind the effects of magnesium deficiency on cardiovascular health are complex, involving oxidation of lipoproteins and effects on biochemical pathways leading to cardiovascular damage. Magnesium deficiency has been shown to result in down regulation of sphingomyelin synthase, along with a decreased synthesis of phosphatidylcholine, and an upregulation of cereamide synthase and biosynthesis of ceramides in cardiovascular tissue [19]. It is suggested that sphingolipids act as regulators of extracellular $\mathrm{Mg}^{2+}$ In a low magnesium state, ceramide synthase is upregulated in ventricular, atrial, aortic smooth muscles, in addition to the release of inflammatory cytokines [20]. Phosphatidylcholine is involved in decreasing the lymphatic absorption of cholesterol and is an important component of HDL, thus furthering the importance of magnesium for maintaining cardiovascular health. Addition- 
ally, low magnesium levels can lead to increased apoptosis of cerebral vascular and peripheral vascular smooth muscle cells, in addition to an upregulation of certain proto-oncogenes that are also involved in atherogenesis and hypertension, including activation of the cell cycle regulator NF- $\kappa$ B and an upregulation of protein kinase $\mathrm{C}$ molecultes [21]-[24].

\section{Premenstrual Syndrome}

Magnesium has been hypothesized to possibly play a role in premenstrual syndrome (PMS). The erythrocyte concentration of magnesium in patients with PMS is significantly lower than that of patients without PMS [25]. It is hypothesized that this is because sex steroid hormones have modulate serum ionized magnesium and calcium levels throughout the menstrual cycle. In the follicular phase of the menstrual cycle, there is elevated serum $\mathrm{Mg}^{2+}$ and a decreased $\mathrm{Ca}^{2+} / \mathrm{Mg}^{2+}$ ratio. However, at time of ovulation, there is a decrease in serum $\mathrm{Mg}^{2+}$. During the luteal phase, there is decrease in $\mathrm{Mg}^{2+}$ and total $\mathrm{Mg}$, as well as $\mathrm{Ca}^{2+}$, proposed to be linked to peaked progesterone concentration. Peak in estrogen concentration is associated with elevated $\mathrm{Ca}^{2+} / \mathrm{Mg}^{2+}$ ratio [26]. Changes in these serum cations can affect the various roles of $\mathrm{Mg}^{2+}$, including vasculature, synaptic transmission, and excitation-contraction coupling. PMS occurs in the luteal phase when there is decreased $\mathrm{Mg}^{2+}$ and increased $\mathrm{Ca}^{2+} / \mathrm{Mg}^{2+}$ ratio; it is proposed that women who are already magnesium deficient may be affected by this cyclical decreased in magnesium.

It has been suggested that many minerals may impact PMS. Limited evidence has suggested that magnesium supplementation, along with vitamin $\mathrm{E}$ and carbohydrate supplementation, may be useful for reducing PMS symptoms, while calcium supplementation was found to be of significant benefit [27]. A study showed that supplementation with both magnesium alone and magnesium plus vitamin B6 significantly decreased severity of PMS in an Iranian population, with the most significant benefit from magnesium plus B6 supplementation [28]. Another open-label preliminary study found that modified-release magnesium $250 \mathrm{mg}$ tablet was effective in improving PMS symptoms in affected women [29]. Additionally, magnesium was shown to have some efficacy in treating menstrual migraines that occur with PMS [30]. However, a case-control study that assessed mineral intake using questionnaires found that while nonheme iron, potassium, and zinc affected PMS risk, magnesium was unrelated to PMS [31]. Additionally, a systematic review of randomized control trials to determine efficacy of 62 herbs, vitamins and minerals for reducing PMS symptoms found that only calcium had evidence to support use in treating PMS [32]. Further research is needed to explore the definitive role of magnesium in treating PMS.

\section{Menopause}

Magnesium is also hypothesized to have a role in menopause, due to the hormonal changes with magnesium demonstrated above. It has been found that there is an inverse relationship between estrogen concentration and serum $\mathrm{Mg}^{2+}$ and total $\mathrm{Mg}$. Serum $\mathrm{Ca}^{2+}$ is also found to be significantly elevated in postmenopausal women. However, the ratio of $\mathrm{Ca}^{2+} / \mathrm{Mg}^{2+}$ is not significantly elevated in postmenopausal women, and this ratio is a better indicator of cardiovascular problems that either cation alone [33]. Emerging research has also suggested that there is a link between menopausal hot flashes and cardiovascular disease risk, though the mechanisms underlying this association are unclear due to the incompletely understood physiology of hot flashes.

Magnesium has been explored to treat symptoms of menopause, including hot flashes and osteoporosis. Hot flashes have been found to be associated with a higher HOMA index, a measure of insulin resistance, and higher glucose levels to a more modest extent [34]. A pilot phase II trial of magnesium supplements to reduce menopause hot flashes in breast cancer patients found that patients who received magnesium oxide had $41.1 \%$ reduced hot flash frequency/week [35].

In dietary supplementation, postmenopausal women on hormone replacement therapy are often supplemented with calcium for osteoporosis treatment, yet are not routinely supplemented with magnesium. While calcium has benefits for bone health in postmenopausal women, low dietary intake of magnesium can be a risk factor for osteoporosis [36]. Magnesium homeostasis is important for bone health in addition to calcium, and low magnesium can affect bones in many ways, including mobilizing magnesium from the bone, slowing matrix calcification, and decreasing bone development, and decreasing bone strength [37] [38]. Additionally, low serum magnesium can decrease the secretion of parathyroid hormone and increase inflammation [29].

While hormonal replacement therapy is a controversial issue in menopausal treatment due to increased cardiovascular risk, it has been suggested that magnesium supplementation can decrease these coagulation risks. De- 
creased dietary magnesium intake decreases serum magnesium levels, thereby increasing the $\mathrm{Ca}^{2+} / \mathrm{Mg}^{2+}$ ratio and thus increasing blood clotting risk [39]. A decreased $\mathrm{Ca}^{2+} / \mathrm{Mg}^{2+}$ ratio would decrease clotting risks. Menopausal women not being treated with hormonal replacement therapy have been found to have lower plasma levels of magnesium than menopausal women treated with hormonal replacement therapy [40]. Estrogen in hormonal replacement shifts magnesium from the circulation to soft and hard tissues. While calcium is often supplemented to treat osteoporosis, this supplementation plus decreased serum $\mathrm{Mg}^{2+}$ can lead to a higher $\mathrm{Ca}^{2+} / \mathrm{Mg}^{2+}$ ratio and lead to intravascular coagulation risks. Magnesium also has antispasmodic effects on the smooth muscle of arteries, thus enhancing the neuroprotective effects of estrogen that may decrease with menopause [41].

\section{Oral Contraceptives}

Oral contraceptives affect serum levels of magnesium. While there are inherent changes with hormone levels discussed above, women on oral contraceptives may have changes in nutritional needs. Women on oral contraceptives are depleted of magnesium, in addition to selenium, zinc, and folic acid, and vitamins B2, B6, B12, C, and E, and may benefit from dietary supplementation [42]. The effect on magnesium is of note specifically because of the inherent risk of thromboembolic events while patients are on oral contraceptives and the effect magnesium has on thromboembolic events. In rat studies, rats that received oral contraceptive pills showed reduced glucose tolerance, reduced plasma HDL, increased plasma LDL, and increased atherogenic indices, while rats that received magnesium in addition to oral contraceptive pills showed less impaired glucose tolerance and less dyslipidemia [43]. Patients on contraceptives have been found to have decreased mean magnesium, zinc, selenium, and phosphorous compared to control groups. This reduction is proportional to the duration of time the patient has been using contraceptives. However, patients on contraceptives have also been found to have increased iron, calcium, and cadmium levels compared to control groups. This is important because it may increase a patient's $\mathrm{Ca}^{2+} / \mathrm{Mg}^{2+}$ ratio, which increases cardiovascular risk in patients [44]. Further studies are needed to explore if magnesium supplementation in humans can decrease the clotting risk associated with OCPs.

\section{PCOS}

Polycystic ovarian syndrome (PCOS) is relevant to magnesium because of its associations with insulin resistance, obesity, and metabolic syndrome; as discussed above, low serum magnesium is associated with insulin resistance. It is unclear if there is a relation between magnesium and PCOS, as different studies have had varying conclusions. It has been shown that patients with PCOS have lower serum $\mathrm{Mg}^{2+}$ and higher serum $\mathrm{Ca}^{2+/} \mathrm{Mg}^{2+}$ ratio, attributes that are associated with insulin resistance, cardiovascular problems, diabetes, and hypertension [45]. One study showed that PCOS patients specifically with insulin resistance exhibited lower serum levels of magnesium [46]. However, other studies have shown that serum magnesium concentrations are indistinguishable between women with and without PCOS, and that while PCOS patients were 19 times greater to have magnesium deficiency, no correlation was found between this decreased magnesium concentration and insulin resistance. After adjusting for calcium concentration, the relationship between magnesium and PCOS was insignificant [47] [48]. This suggests that calcium concentration is related to PCOS, however, which would affect the $\mathrm{Ca}^{2+} / \mathrm{Mg}^{2+}$ ratio and thus cardiovascular risk factors. A study in which PCOS patients were treated with magnesium oxide showed no change in free fatty acids, which if elevated can result in the development of insulin resistance. However, this study used a dosage of $400 \mathrm{mg}$ of magnesium oxide twice daily, while other studies have shown increased effects with higher doses of $2.5 \mathrm{~g}$ of magnesium chloride daily, suggesting that a higher dosage would be needed to reveal an effect [49]. A study in IVF patients undergoing ovarian hyperstimulation showed that an increase in serum estrogen was associated with decreased ionized magnesium, and an increase in serum progesterone was associated with an increase in the $\mathrm{Ca}^{2+} / \mathrm{Mg}^{2+}$ ratio [50]. Additionally, while it is well known that OCPs increase the risk of venous thromboembolism in patients, recent studies have shown that women with PCOS on OCPs are at a further increased risk for venous thromboembolism [51]. The relationship of increased VTE risk to magnesium deficiency in women with PCOS should be explored.

\section{Endometriosis}

Magnesium can also be explored in its relation to endometriosis. Endometriosis has an inflammatory component, and as discussed above, magnesium is involved in inflammatory processes. Magnesium also has a role in relaxing smooth muscle [52]. Magnesium intake from food sources has been found to have an inverse relationship 
with endometriosis [53]. One study found no difference in levels of total and ionized magnesium in endometriosis vs. control patients, though it was noted that participants in this study were taking various vitamin supplements [54]. Further studies are necessary to explore the role of magnesium in endometriosis further.

\section{Gynecological Surgery}

Magnesium can also serve an important role in preventing thromboembolic events in patients after gynecological surgery. Magnesium sulfate has been shown in in vivo experiments to reduce mortality in induced acute thromboembolismin mice [55]. It has been shown that after cholecystectomy, higher levels of magnesium were found in patients who did not develop thrombosis of the lower limbs compared to those who did [56]. The role of magnesium in preventing thromboembolic events in patients after gynecological surgery has not yet been explored, but perhaps would show similar results.

\section{Cancer}

Magnesium plays an interesting role in cancer, not only due to the association with inflammation discussed, but also due to its role in the cell cycle and proliferation, as discussed above [57]. Magnesium is needed to maintain genomic stability by stabilizing DNA and chromatin, regulating cell proliferation, and act as an enzymatic cofactor for DNA processing and removal of regions of DNA damage [58] [59]. Therefore, hypomagnesemia could potentially lead to increasing DNA mutations and unregulated cell cycling. Magnesium has also been linked to increased oxidative stress [60].

Decreased dietary intake of magnesium has been linked to various cancers. High magnesium concentration in drinking water has been linked to lower death rates of breast, prostate, and ovarian cancers [61]-[63]. In addition, an increased intake of magnesium is associated with a decreased risk of colorectal cancer in women [64] [65]. Interestingly, magnesium has been found to modify the effects of certain nitrates in drinking water on the development of colon cancer; colon cancer is linked to high nitrate levels in drinking water [66]. This may be due to the fact that low dietary intake of magnesium is associated with poor DNA repair capacity [67]. An increased $\mathrm{Ca}^{2+} / \mathrm{Mg}^{2+}$ ratio could also have consequences in cancer development in addition to cardiovascular effects. It has been suggested that an increased ratio could even potentially lead to increased risk for postmenopausal breast cancer [68].

Additionally, hypomagnesemia is frequently seen in cancer patients, often in the terminal stages [69]. Decreased dietary intake, GI losses, urinary losses due to medications, chemotherapy, and intrinsic causes due to malignancy itself may be causes of this [70]. Hypomagnesia is associated with increased mortality rates in hospitalized patients [71].

Elderly patients or patients with kidney disease can't handle ingested magnesium as well, resulting in hypermagnesemia. Side effects of high magnesium levels include nausea, vomiting, lethargy, low blood pressure, low pulse rate, difficulty breathing, and in extreme cases, coma and death. Even in younger patients with normal kidneys, magnesium sulfate should not be used at a dose of more than $10 \mathrm{gm}$ per day or for more than one week without a doctor's supervision [72].

\section{Conclusion}

Magnesium is extremely relevant to women's health issues, with more knowledge yet to come on the relationship between magnesium and gynecology. The levels of magnesium vary throughout the menstrual cycle and are closely related to the levels of calcium. This is extremely relevant to women, for the ratio of $\mathrm{Ca}^{2+} / \mathrm{Mg}^{2+}$ can affect cardiovascular event risk, venous thromboembolism risk, and possibly even PCOS. The contributions of magnesium to the field of women's health are far reaching, spanning effects on PMS to menopause. Magnesium supplementation has shown promise in treating PMS and menstrual migraines, hot flashes, and even decreasing breast and ovarian cancer risk. The effects of magnesium deficiency on other gynecological conditions, such as fibroids, uterine polyps, and pelvic inflammatory disease have not yet been thoroughly explored, though could show promising contributions.

\section{Acknowledgements}

We would like to thank Dr. Burton Artura and Dr. Bella Artura for their generous advice and contributions to 
this review article.

\section{References}

[1] Yokoyama, K., Takahashi, N., Yada, Y., et al. (2010) Prolonged Maternal Magnesium Administration and Bone Metabolism in Neonates. Early Human Development, 86, 187-191. http://dx.doi.org/10.1016/j.earlhumdev.2010.02.007

[2] Guerrera, M.P., Volpe, S.L. and Mao, J.J. (2009) Therapeutic Uses of Magnesium. American Family Physician, 80, 157.

[3] Assadi, F. (2010) Hypomagnesemia: An Evidence-Based Approach to Clinical Cases. Iranian Journal of Kidney Diseases, 4, 13.

[4] Saris, N.E.L., Mervaala, E., Karppanen, H., et al. (2000) Magnesium: An Update on Physiological, Clinical and Analytical Aspects. Clinica Chimica Acta, 294, 1-26. http://dx.doi.org/10.1016/S0009-8981(99)00258-2

[5] Altura, B.T. and Altura, B.M. (1980) Withdrawal of Magnesium Causes Vasospasm While Elevated Magnesium Produces Relaxation of Tone in Cerebral Arteries. Neuroscience Letters, 20, 323-327. http://dx.doi.org/10.1016/0304-3940(80)90168-8

[6] Altura, B.T. and Altura, B.M. (1981) Magnesium Ions and Contraction of Vascular Smooth Muscles: Relationship to Some Vascular Diseases. Federation Proceedings, 40, 2672.

[7] Swaminathan, R. (2003) Magnesium Metabolism and Its Disorders. The Clinical Biochemist Reviews, 24, 47.

[8] Ford, E.S. and Mokdad, A.H. (2003) Dietary Magnesium Intake in a National Sample of US Adults. The Journal of Nutrition, 133, 2879-2882.

[9] Nielsen, F.H. (2010) Magnesium, Inflammation, and Obesity in Chronic Disease. Nutrition Reviews, 68, 333-340. http://dx.doi.org/10.1111/j.1753-4887.2010.00293.X

[10] Rayssiguier, Y., Libako, P., Nowacki, W., et al. (2010) Magnesium Deficiency and Metabolic Syndrome: Stress and Inflammation May Reflect Calcium Activation. Magnes Res, 23, 73-80.

[11] Evangelopoulos, A.A., Vallianou, N.G., Panagiotakos, D.B., et al. (2008) An Inverse Relationship between Cumulating Components of the Metabolic Syndrome and Serum Magnesium Levels. Nutrition Research, 28, 659-663. http://dx.doi.org/10.1016/j.nutres.2008.07.001

[12] Weglicki, W.B. (2012) Hypomagnesemia and Inflammation: Clinical and Basic Aspects. Annual Review of Nutrition, 32, 55-71. http://dx.doi.org/10.1146/annurev-nutr-071811-150656

[13] Shay, C.M., Van Horn, L., Stamle, J., Dyer, A.R., et al. (2012) Food and Nutrient Intakes and Their Associations with Lower BMI in Middle-Aged US Adults: The International Study of Macro-/Micronutrients and Blood Pressure (INTERMAP). The American Journal of Clinical Nutrition, 96, 483-491. http://dx.doi.org/10.3945/ajcn.111.025056

[14] Fung, T.T., Manson, J.E., Solomon, C.G., et al. (2003) The Association between Magnesium Intake and Fasting Insulin Concentration in Healthy Middle-Aged Women. Journal of the American College of Nutrition, 22, 533-538. http://dx.doi.org/10.1080/07315724.2003.10719332

[15] Barbagallo, M., Dominguez, L.J., Galiot, A., et al. (2003) Role of Magnesium in Insulin Action, Diabetes and Cardio-Metabolic Syndrome X. Molecular Aspects of Medicine, 24, 39-52. http://dx.doi.org/10.1016/S0098-2997(02)00090-0

[16] Lima, L., Cruz, T., Rodrigues, L.E., et al. (2009) Serum and Intracellular Magnesium Deficiency in Patients with Metabolic Syndrome-Evidences for Its Relation to Insulin Resistance. Diabetes Research and Clinical Practice, 83, 257262. http://dx.doi.org/10.1016/j.diabres.2008.11.019

[17] Guerrero-Romero, F. and Rodríguez-Morán, M. (2011) Magnesium Improves the Beta-Cell Function to Compensate Variation of Insulin Sensitivity: Double-Blind, Randomized Clinical Trial. European Journal of Clinical Investigation, 41, 405-410. http://dx.doi.org/10.1111/j.1365-2362.2010.02422.x

[18] Zhang, W., Iso, H., Ohira, T., Date, C. and Tamakoshi, A. (2012) Associations of Dietary Magnesium Intake with Mortality from Cardiovascular Disease: The JACC Study. Atherosclerosis, 221, 587-595. http://dx.doi.org/10.1016/j.atherosclerosis.2012.01.034

[19] Altura, B.M., Shah, N.C., Li, Z., et al. (2010) Magnesium Deficiency Upregulates Serine Palmitoyl Transferase (SPT 1 and SPT 2) in Cardiovascular Tissues: Relationship to Serum Ionized Mg and Cytochrome c. The American Journal of Physiology — Heart and Circulatory Physiology, 299, H932-H938. http://dx.doi.org/10.1152/ajpheart.01076.2009

[20] Altura, B.M., Shah, N.C., Zhang, A., et al. (2012) Short-Term Magnesium Deficiency Upregulates Ceramide Synthase in Cardiovascular Tissues and Cells: Cross-Talk among Cytokines, $\mathrm{Mg}^{2+}, \mathrm{NF}-\kappa \mathrm{B}$, and de Novo Ceramide. The American Journal of Physiology — Heart and Circulatory Physiology, 302, H319-H332. http://dx.doi.org/10.1152/ajpheart.00453.2011 
[21] Altura, B.M., Nilank, N.C., Jiang, X.C., et al. (2009) Short-Term Magnesium Deficiency Results in Decreased Levels of Serum Sphingomyelin, Lipid Peroxidation, and Apoptosis in Cardiovascular Tissues. The American Journal of Physiology—Heart and Circulatory Physiology, 297, H86-H92. http://dx.doi.org/10.1152/ajpheart.01154.2008

[22] Altura, B.M., Shah, N.C., Shah, G.J., et al. (2013) Magnesium Deficiency Upregulates Sphingomyelinases in Cardiovascular Tissues and Cells: Cross-Talk among Proto-Oncogenes, $\mathrm{Mg}(2+)$, NF- $\kappa \mathrm{B}$ and Ceramide and Their Potential Relationships to Resistant Hypertension, Atherogenesis and Cardiac Failure. International Journal of Clinical and Experimental Medicine, 6, 861-879.

[23] Shah, N.C., Liu, J.P., Iqbal, J., et al. (2011) Mg Deficiency Results in Modulation of Serum Lipids, Glutathione, and NO Synthase Isozyme Activation in Cardiovascular Tissues: Relevance to de Novo Synthesis of Ceramide, Serum Mg and Atherogenesis. International Journal of Clinical and Experimental Medicine, 4, 103-118.

[24] Altura, B.M., Shah, N.C., Shah, G.J., et al. (2014) Short-Term Mg Deficiency Upregulates Protein Kinase C Isoforms in Cardiovascular Tissues and Cells; Relation to NF- $\kappa$ B, Cytokines, Ceramide Salvage Sphingolipid Pathway and PKC-Zeta: Hypothesis and Review. International Journal of Clinical and Experimental Medicine, 7, 1-21.

[25] Sherwood, R.A., Rocks, B.F., Stewart, A. and Saxton, R.S. (1986) Magnesium and the Premenstrual Syndrome. Annals of Clinical Biochemistry, 23, 667-670. http://dx.doi.org/10.1177/000456328602300607

[26] Muneyyirci-Delale, O., Nacharaju, V.L., Altura, B.M. and Altura, B.T. (1998) Sex Steroid Hormones Modulate Serum Ionized Magnesium and Calcium Levels throughout the Menstrual Cycle in Women. Fertility and Sterility, 69, 958962. http://dx.doi.org/10.1016/S0015-0282(98)00053-3

[27] Bendich, A. (2000) The Potential for Dietary Supplements to Reduce Premenstrual Syndrome (PMS) Symptom. Journal of the American College of Nutrition, 19, 3-12. http://dx.doi.org/10.1080/07315724.2000.10718907

[28] Fathizadeh, N., Ebrahimi, E., Valiani, M., Tavakoli, N. and Yar, M.H. (2010) Evaluating the Effect of Magnesium and Magnesium plus Vitamin B6 Supplement on the Severity of Premenstrual Syndrome. Iranian Journal of Nursing and Midwifery Research, 15, 401-405.

[29] Quaranta, S., Buscaglia, M.A., Meroni, M.G., Colombo, E. and Cella, S. (2007) Pilot Study of the Efficacy and Safety of a Modified-Release Magnesium 250mg Tablet (Sincromag ${ }^{\circledR}$ ) for the Treatment of Premenstrual Syndrome. Clinical Drug Investigation, 27, 51-58. http://dx.doi.org/10.2165/00044011-200727010-00004

[30] Allais, G., Gabellari, I.C., Burzio, C., et al. (2012) Premenstrual Syndrome and Migraine. Neurological Science, 33, 111-115. http://dx.doi.org/10.1007/s10072-012-1054-5

[31] Chocano-Bedoya, P.O., Manson, J.E., Hankinson, S.E., et al. (2013) Intake of Selected Minerals and Risk of Premenstrual Syndrome. American Journal of Epidemiology, 177, 1118-1127. http://dx.doi.org/10.1093/aje/kws363

[32] Whelan, A.M., Jurgens, T.M. and Naylor, H. (2009) Herbs, Vitamins and Minerals in the Treatment of Premenstrual Syndrome: A Systematic Review. The Canadian Journal of Clinical Pharmacology, 16, e407-e429.

[33] Muneyyirci-Delale, O., Nacharaju, V.L., Dalloul, M., Altura, B.M. and Altura, B.T. (1999) Serum Ionized Magnesium and Calcium in Women after Menopause: Inverse Relation of Estrogen with Ionized Magnesium. Fertility and Sterility, 71, 869-872. http://dx.doi.org/10.1016/S0015-0282(99)00065-5

[34] Thurston, R.C., El Khoudary, S.R., Sutton-Tyrrell, K., et al. (2012) Vasomotor Symptoms and Insulin Resistance in the Study of Women's Health Across the Nation. Journal of Clinical Endocrinology \& Metabolism, 97, 3487-3494. http://dx.doi.org/10.1210/jc.2012-1410

[35] Park, H., Parker, G.L., Boardman, C.H., et al. (2011) A Pilot Phase II Trial of Magnesium Supplements to Reduce Menopausal Hot Flashes in Breast Cancer Patients. Supportive Care in Cancer, 19, 859-863. http://dx.doi.org/10.1007/s00520-011-1099-7

[36] Rude, R.K., Gruber, H.E., Norton, H.J., Wei, L.Y., Frausto, A. and Kilburn, J. (2005) Dietary Magnesium Reduction to 25\% of Nutrient Requirement Disrupts Bone and Mineral Metabolism in the Rat. Bone, 37, 211-219. http://dx.doi.org/10.1016/j.bone.2005.04.005

[37] Castiglioni, S., Cazzaniga, A., Albisetti, W. and Maier, J.A.M. (2013) Magnesium and Osteoporosis: Current State of Knowledge and Future Research Directions. Nutrients, 5, 3022-3033. http://dx.doi.org/10.3390/nu5083022

[38] Creedon, A., Flynn, A. and Cashman, K. (1999) The Effect of Moderately and Severely Restricted Dietary Magnesium Intakes on Bone Composition and Bone Metabolism in the Rat. British Journal of Nutrition, 82, 63-71.

[39] Seelig, M.S. (1990) Increased Need for Magnesium with the Use of Combined Oestrogen and Calcium for Osteoporosis Treatment. Magnesium Research: Official Organ of the International Society for the Development of Research on Magnesium, 3, 197-215.

[40] Jurczak, A., Brodowski, J., Grochans, E., et al. (2013) Effect of Menopausal Hormone Therapy on the Levels of Magnesium, Zinc, Lead and Cadmium in Post-Menopausal Women. Annals of Agricultural and Environmental Medicine: AAEM, 20, 147-151.

[41] Seelig, M.S., Altura, B.M. and Altura, B.T. (2004) Benefits and Risks of Sex Hormone Replacement in Postmenopaus- 
al Women. Journal of the American College of Nutrition, 23, 482S-496S. http://dx.doi.org/10.1080/07315724.2004.10719387

[42] Palmery, M., Saraceno, A., Vaiarelli, A. and Carlomagno, G. (2013) Oral Contraceptives and Changes in Nutritional Requirements. European Review for Medical and Pharmacological Sciences, 17, 1804-1813.

[43] Olatunji, L.A., Oyeyipo, I.P., Micheal, O.S. and Soladoye, A.O. (2008) Effect of Dietary Magnesium on Glucose Tolerance and Plasma Lipid during Oral Contraceptive Administration in Female Rats. African Journal of Medicine and Medical Sciences, 37, 135-139.

[44] Akinloye, O., Adebayo, T.O., Oguntibeju, O.O., Oparinde, D.P. and Ogunyemi, E.O. (2011) Effects of Contraceptives on Serum Trace Elements, Calcium and Phosphorus Levels. West Indian Medical Journal, 60, 308-315.

[45] Muneyyirci-Delale, O., Nacharaju, V.L., Dalloul, M., et al. (2001) Divalent Cations in Womenwith PCOS: Implications for Cardiovascular Disease. Gynecological Endocrinology, 15, 198-201. http://dx.doi.org/10.1080/gye.15.3.198.201

[46] Chakraborty, P., Ghosh, S., Goswami, S.K., et al. (2013) Altered Trace Mineral Milieu Might Play an Aetiological Role in the Pathogenesis of Polycystic Ovary Syndrome. Biological Trace Element Research, 152, 9-15.

[47] Kauffman, R.P., Tullar, P.E., Nipp, R.D. and Castracane, V.D. (2011) Serum Magnesium Concentrations and Metabolic Variables in Polycystic Ovary Syndrome. Acta Obstetricia et Gynecologica Scandinavica, 90, 452-458. http://dx.doi.org/10.1111/j.1600-0412.2010.01067.x

[48] Sharifi, F., Mazloomi, S., Hajihosseini, R., et al. (2012) Serum Magnesium Concentrations in Polycystic Ovary Syndrome and Its Association with Insulin Resistance. Gynecological Endocrinology, 28, 7-11. http://dx.doi.org/10.3109/09513590.2011.579663

[49] Muneyyirci-Delale, O., Kaplan, J., Joulak, I., et al. (2013) Serum Free Fatty Acid Levels in PCOS Patients Treated with Glucophage, Magnesium Oxide and Spironolactone. Gynecological Endocrinology, 29, 474-477. http://dx.doi.org/10.3109/09513590.2013.769515

[50] O’Shaughnessy, A., Muneyyirci-Delale, O., Nacharaju, V.L., et al. (2001) Circulating Divalent Cations in Asymptomatic Ovarian Hyperstimulation and in Vitro Fertilization Patients. Gynecologic and Obstetric Investigation, 52, 237242. http://dx.doi.org/10.1159/000052982

[51] Bird, S.T., Hartzema, A.G., Brophy, J.M., et al. (2013) Risk of Venous Thromboembolism in Women with Polycystic Ovary Syndrome: A Population-Based Matched Cohort Analysis. Canadian Medical Association Journal, 185, E115E120. http://dx.doi.org/10.1503/cmaj.120677

[52] D’Angelo, E.K., Singer, H.A. and Rembold, C.M. (1992) Magnesium Relaxes Arterial Smooth Muscle by Decreasing Intracellular $\mathrm{Ca}^{2+}$ without Changing Intracellular $\mathrm{Mg}^{2+}$. The Journal of Clinical Investigation, 89, 1988-1994. http://dx.doi.org/10.1172/JCI115807

[53] Harris, H.R., Chavarro, J.E., Malspeis, S., et al. (2013) Dairy-Food, Calcium, Magnesium, and Vitamin D Intake and Endometriosis: A Prospective Cohort Study. American Journal of Epidemiology, 177, 420-430. http://dx.doi.org/10.1093/aje/kws247

[54] Muneyyirci-Delale, O. and Altura, B.T. (2013) Personal Communication.

[55] Shen, M.Y., Sheu, J.R., Hsiao, G., Lee, Y.M. and en, M.H. (2003) Antithrombotic Effects of Magnesium Sulfate in in Vivo Experiments. International Journal of Hematology, 77, 414-419. http://dx.doi.org/10.1007/BF02982655

[56] Kopański, Z., Schlegel-Zawadzka, M., Piekoszewski, W., Sadlik, K. and Sibiga, W. (2000) The Disturbances of Magnesium in Patients with Thromboembolic Complications after a Cholecystectomy. Thrombosis Research, 99, 571-575. http://dx.doi.org/10.1016/S0049-3848(00)00278-4

[57] Castiglioni, S. and Maier, J.A. (2011) Magnesium and Cancer: A Dangerous Liason. Magnesium Research, 24, S92S100.

[58] Hartwig A. (2001) Role of Magnesium in Genomic Stability. Mutation Research/Fundamental and Molecular Mechanisms of Mutagenesis, 475, 113-121. http://dx.doi.org/10.1016/S0027-5107(01)00074-4

[59] Rubin, H. (2005) Magnesium: The Missing Element in Molecular Views of Cell Proliferation Control. BioEssays, 27, 311-320. http://dx.doi.org/10.1002/bies.20183

[60] Hans, C.P., Chaudhary, D.P. and Bansal, D.D. (2002) Magnesium Deficiency Increases Oxidative Stress in Rats. Indian Journal of Experimental Biology, 40, 1275-1279.

[61] Yang, C.Y., Chiu, H.F., Tsai, S.S., et al. (2000) Calcium and Magnesium in Drinking Water and Risk of Death from Prostate Cancer. Journal of Toxicology and Environmental Health, Part A: Current Issues, 60, 17-26. http://dx.doi.org/10.1080/009841000156565

[62] Yang, C.Y., Chiu, H.F., Tsai, S.S., Wu, T.N. and Chang, C.C. (2002) Calcium and Magnesium in Drinking Water and the Risk of Death from Esophageal Cancer. Magnesium Research, 15, 215-222. 
[63] Chiu, H.F., Chang, C.C. and Yang, C.Y. (2004) Calcium and Magnesium in Drinking Water and the Risk of Death from Ovarian Cancer. Magnesium Research, 17, 28-34.

[64] Larsson, S.C., Bergkvist, L. and Wolk, A. (2005) Magnesium Intake in Relation to Risk of Colon Cancer in Women. Journal of the American Medical Association, 293, 86-89. http://dx.doi.org/10.1001/jama.293.1.86

[65] Folsom, A.R. and Hong, C.P. (2006) Magnesium Intake and Reduced Risk of Colon Cancer in a Prospective Study of Women. American Journal of Epidemiology, 163, 232-235. http://dx.doi.org/10.1093/aje/kwj037

[66] Chiu, H.F., Tsai, S.S., Wu, T.N. and Yang, C.Y. (2010) Colon Cancer and the Content of Nitrate and Magnesium in Drinking Water. Magnesium Research, 23, 81-89.

[67] Mahabir, S., Wei, Q., Barrera, S., et al. (2008) Dietary Magnesium and DNA Repair Capacity as Risk Factors for Lung Cancer. Carcinogenesis, 29, 949-956. http://dx.doi.org/10.1093/carcin/bgn043

[68] Sahmoun, A.E. and Singh, B.B. (2010) Does a Higher Ratio of Serum Calcium to Magnesium Increase the Risk for Postmenopausal Breast Cancer? Medical Hypotheses, 75, 315-318. http://dx.doi.org/10.1016/j.mehy.2010.02.037

[69] D’Erasmo, E., Celi, F.S., Acca, M., Minisola, S., Aliberti, G. and Mazzuoli, G.F. (1991) Hypocalcemia and Hypomagnesemia in Cancer Patients. Biomedicine \& Pharmacotherapy, 45, 315-317. http://dx.doi.org/10.1016/0753-3322(91)90087-a

[70] Saif, M.W. (2008) Management of Hypomagnesemia in Cancer Patients Receiving Chemotherapy. The Journal of Supportive Oncology, 6, 243-248.

[71] Rubiez, G.J., Thill-Bahorozian, M., Hardie, D., et al. (1993) Association of Hypomagnesemia and Mortality in Acutely Ill Medical Patients. Critical Care Medicine, 21, 203-209. http://dx.doi.org/10.1097/00003246-199302000-00010

[72] Babyatsky, M. (2007) How Much Is Too Much Magnesium Sulfate? IBS Center, Everyday Health.com 2007. Web. 9 Mar. 2016.

[73] Magnesium Ion. PubChem, The PubChem Project 2016. Web. 9 Mar. 2016.

\section{Appendix}

Magnesium Ion Chemical Formula [73].

Chemical Names: Magnesium ion; Magnesium (2+); Magnesium cation; Magnesium ions; Magnesium, ion $\left(\mathrm{Mg}^{2+}\right) ; \mathrm{Mg}^{++}$;

Molecular Formula: $\mathrm{Mg}^{2+}$.

Molecular Weight: 24.305 g/mol. 